\title{
Otomatisasi Pendistribusian Zakat Pada Badan Amil Zakat Nasional Prov. Kep. Bangka Belitung
}

\author{
Yuyi Andrika ${ }^{* 1}$, Melati Suci Mayasari $^{2}$, Harrizki Arie Pradana $^{3}$, Fitriyani $^{4}$ \\ ${ }_{1,2,3,4}$ ISB Atma Luhur Pangkalpinang \\ Jurusan Sistem Informasi, Fakultas Teknologi Informatika ISB Atma Luhur, Pangkal Pinang \\ *1yuyiandrika@atmaluhur.ac.id, ${ }^{*}$ imeal_melati@atmaluhur.ac.id, \\ ${ }^{3}$ harrizkiariep@atmaluhur.ac.id, ${ }^{4}$.fitriyani@atmaluhur.ac.id
}

\begin{abstract}
Abstrak
Baznas Prov. Kep. Bangka Belitung merupakan badan pengelola zakat yang didirikan berdasarkan undang-undang nomor 38 tahun 1999. Baznas merupakan badan yang menghimpun dan menyalurkan zakat yang diperoleh. Dalam proses penyaluran zakat, terdapat hal-hal yang dinilai masih kurang efektif antara lain pendataan penduduk yang sudah pernah mendapatkan dan yang belum pernah mendapatkan masih tumpang tindih, serta masih terjadinya kesulitan dalam pembuatan dokume yang dibutuhkan dalam proses penyaluran zakat dan infaq. Dengan adanya masalah tersebut dalam penelitian diusulkan untuk membangun sebuah sistem yang terkomputerisasi. Metode berorientasi objek dengan menggunakan Unified Modelling Language sebagai tools digunakan dalam analisis maupun perancangannya. Teknologi yang digunakan dalam pengembangan perangkat lunak sistem menggunakan Php sebagai bahasa pemrogramannya dan My SQL sebagai database. Sistem ini diharapkan dapat meningkatkan kinerja Baznas Prov. Kep. Bangka Belitung dalam hal penyaluran zakat.
\end{abstract}

Kata kunci: Baznas, Sistem Penyaluran zakat, infaq.

\begin{abstract}
Baznas Prov. Kep. Bangka Belitung is a zakat management body which was established based on law number 38 of 1999. Baznas is an agency that collects and distributes the zakat that is obtained. In the process of distributing zakat, there are things that are deemed ineffective, including overlapping data on residents who have received and who have never received it, as well as difficulties in making documents needed in the process of distributing zakat and infaq. Given these problems in the study it is proposed to build a computerized system. Object-oriented methods using the Unified Modeling Language as a tool used in the analysis and design. The technology used in system software development uses Phpp as the programming language and My SQL as the database. This system is expected to improve the performance of Baznas Prov. Kep. Bangka Belitung in terms of zakat distribution.
\end{abstract}

Keywords: Baznas, Zakat Distribution System, infaq. 


\section{PENDAHULUAN}

\subsection{Latar Belakang}

Dalam penghimpunan zakat di wilayah Bangka Belitung, BAZNAS Prov. Kep. Bangka Belitung terus mengalami peningkatan. BAZNAS Prov. Kep. Bangka Belitung juga berusaha untuk meningkatkan penyaluran zakat kepada 8 (delapan) asnaf yang telah ditentukan dalam Al Qur'an Surah At Taubah ayat 60.

Semakin banyaknya transaksi penyaluran zakat, tentunya semakin banyak juga proses yang harus terekam dengan baik agar dapat mengurangi resiko kekeliruan data di kemudian hari. Proses pencatatan yang dilakukan secara manual dinilai sudah sangat sulit dilakukan terutama ketika akan diperlukannya data dalam waktu yang cukup singkat. Diperlukan sebuah sistem yang mampu menampung semua aktifitas mulai dari pendataan, pencatatan proses transaksi hingga pelaporan agar BAZNAS Prov. Kep. Bangka Belitung lebih dapat meningkatkan pelayanan dan meningkatkan kinerja dalam bidang penyaluran zakat.

Berdasarkan latar belakang masalah tersebut, penelitian memandang penting mengangkat masalah diatas ke dalam skripsi dengan mengambil judul Rancang Bangun Sistem Informasi Manajemen Pendataan dan Pendistribusian Zakat pada Badan Amil Zakat Nasional Prov. Kep. Bangka Belitung Berbasis online.

\subsection{Masalah}

Berdasarkan latar belakang masalah diatas, maka dapat diidentifikasi masalah pada bidang pendistribusian sebagai berikut:

a. Banyaknya proses yang dilakukan manual dinilai tak lagi efektif untuk bersaing di era teknologi sekarang ini.

b. Arsip Fisik yang sering sering hilang,

c. Diperlukan sistem yang dapat mudah digunakan oleh pengguna,

d. Sistem yang dibangun mulai dari proposal masuk, pendataan mustahiq berdasarkan kategori, segala jenis transaksi penyantunan mustahiq berdasarkan jenis kategori, hingga pembuatan laporan.

\subsection{Tujuan}

Tujuan yang hendak dicapai dalam penelitian antara lain:

a. Untuk mengetahui proses kerja pada Bid. Pendistribusian di Baznas Prov. Kep. Bangka Belitung,

b. Untuk mengetahui proses transaksi yang terjadi pada Bid. Pendistribusian Baznas Prov. Kep. Bangka Belitung,

c. Memberikan solusi proses kerja dengan sistem yang akan dibangun,

d. Membantu Baznas Prov. Kep. Bangka Belitung menjadi lembaga yang lebih modern dan canggih.

\section{METODE PENELITIAN}

\subsection{Metodologi Penelitian}

Pada penelitian ini menggunakan metode deskriptif, dimana metode yang menggambarkan suatu keadaan atau permasalahan yang sedang terjadi berdasarkan fakta dan data- data yang diperoleh dan dikumpulkan pada waktu melaksanakan penelitian.

Yuyi Andrika, et., al [Otomatisasi Pendistribusian Zakat Pada Badan Amil Zakat Nasional Prov. Kep. Bangka Belitung] 


\subsection{Model Pengembangan Sistem}

Penlitian ini menggunakan model FAST (Framework for the Application of Systems Thinking) didalam pengembangan sistemnya, dimana model FAST yang digunakan dalam penelitian ini terdiri dari:
a. Fase Penyelidikan awal
b. Fase Analisis Masalah
c. Fase Analisis Kebutuhan
d. Fase Desain Logis.
e. Fase Konstruksi
f. Fase Implementasi
g. Fase Operasi dan Tahap Dukungan.

\subsection{Fase Penyelidikan Awal}

Penyelidikan awal dilakukan dengan cara melakukan observasi dan wawancara di BAZNAS Prov. Kep. Bangka Belitung, dimana fase ini dilakukan untuk memperoleh data dan data tersebut akan digunakan untuk menentukan cakupan sistem.

\section{$2.4 \quad$ Fase Analisis Masalah}

Dalam fase ini mempelajari wilayah permasalahan yang ditemukan, menganalisis permasalahan atau kesempatan berserta proses bisnisnya.

\subsection{Fase Analisis Kebutuhan}

Pada tahap ini analisis kebutuhan dilakukan pengumpulan dan analisis data, terutama menyangkut kebutuhan para pengguna sistem dan menilai kekuatan maupun kelemahan metode kerja yang telah diterapkan selama ini, dengan cara mengumpulkan Dokumen, meliputi pedoman kerja, form pemasukan data dan pelaporan, diagram kerja, bagian organisasi untuk melihat hirarki wewenang dan tanggung jawab, dan lain-lain.

\subsection{Fase Desain Logis}

Pada fase ini, hasil dari analisis kebutuhan akan diterjemahkan menjadi gambar-gambar yang disebut model sistem. Desain logis lebih lanjut mendokumentasikan persyaratan bisnis dengan menggunakan model- model sistem yang menggambarkan proses bisnis.

\subsection{Fase Konstruksi}

Tujuan pada tahap ini adalah membangun dan menguji sebuah sistem yang memenuhi persyaratan bisnis dan sertifikasi desain fisik, mengimplementasikan antarmuka antara sistem yang baru dengan sistem yang lama, dalam rangka membangun suatu sistem informasi yang dapat membantu proposal dalam mendapatkan informasi akademik pembelajaran dan informasiinformasi terbaru di sekolah yang akan dikembangkan menggunakan $P H P$ dan $M y S Q L$.

\subsection{Fase Implementasi}

Tahapan ini dilakukan pengujian terhadap sistem yang akan diimplementasikan dengan black box.

\subsection{Alat Bantu Pengembangan Sistem.}

Pengembangan sistem menggunakan tools UML (Unified Modelling Languange), dengan menggunakan use case diagram. 


\subsection{Tinjauan Penelitian}

Penelitian sebelumnya yang pernah dilakukan yang berkaitan dengan penyaluran zakat dijadikan sebagai referensi penelitian adalah sebagai berikut:

a. Penelitian dari [1] menekankan bahawa masalah yang terdapat dalam penelitiannya adalah apakah pendistribusian zakat dapat mensejahterakan masyarakat. Penelitian menggunakan analisis deskriftif dengan responden kurang dari 100. Hasil yang didapatkan dari penelitian BAZMAL berpengaruh signifikan terhadap peningkatan sebesar $25,2 \%$, pendidikan sebesar $22.9 \%$ dan kesehatan sebesar $8,9 \%$.

b. Menurut penelitian [2], hasil dari penelitiannya yang menggunakan deskripsi kualitatif dengan pendekatan studi kasus. Tujuan penelitian mengungkap pengelolaan zakat perusahaan pada Bosown Group Financial Service Makasar. Hasil menunjukkan bahwa perhitungan zakat pada Bosowa Group dilakukan ketika jumlah laba perusahaan memenuhi nisab yang dihitung berdasarkan ketentuan 2,5\%. Ketika perusahaan tidak mendapatkan laba, maka pengeluaran kegiatan amal diakui sebagai sedekah.

c. Sedangkan [3] dalam penelitiannya memiliki tujuan menganalisis efektifitas distribusi dana ZIS pada sekolah SMA Terbuka yang dibina LAZ Zakat Sukses, Depok. Hasilnya dari ratarata skor tingkat efektifitas program menunjukkan nilai 3,11. Artinya nilai masuk dalam rentang skala efektif. Sehingga penyaluran dana ZIS dalam bentuk bantuan operasional sekolah SMA terbuka binaan LAZ Zakat Sukses Depok Efektif.

d. Begitu juga dengan [4], menghasilkan tujuan penyaluran zakat tepat sasaran dengan menggunakan sistem informasi. Metode yang digunakan Fuzzy C-Means. Hasil penelitian akurasi perhitungan terdapat 8 data yang benar dari 10 data yang diuji coba.

e. Didalam penelitian yang dilakukan oleh [5] yang bertujuan agar pengelolaan zakat dapat mempermudah bagian keuangan dalam mengelola zakat. Hasil yang diperoleh dengan sistem informasi pengelolaan zakat menjadi efektif dan efisien.

f. Dalam penelitiannya dengan tujuan dengan sistem informasi penyaluran zakat kepada mustahiq menjadi mudah. Metode yang digunakan Blackbox testing dengan model waterfall [7].

g. Dan menurut penelitian dari [8] bertujuan untuk mempertemukan kebutuhan Muzakki dan Mustahik. Metode yang digunakan adalah extreme programming.

\section{HASIL DAN PEMBAHASAN}

\subsection{Proses Bisnis}

Berikut merupakan proses bisnis yang terdapat di dalam BAZNAS Prop. Kep. Bangka Belitung didalam menyalurkan zakat:

a. Setelah proposal didaftar, BAZNAS Prov. Kep. Bangka Belitung menyiapkan tim survey dan mensurvey ke tempat tinggal mustahiq untuk memastikan kebenaran data calon mustahiq.

b. Pada proses survey, calon mustahiq diberikan form survey kemudian diisi. Setelah disurvey, Hasil survey dirapatkan ke pengurus BAZNAS Prov. Kep. Bangka Belitung untuk mendapatkan keputusan bersama dan menentukan bantuan yang akan diberikan.

c. Jika hasil survey data mustahiq mencapai syarat-syarat tertentu, maka calon mustahiq di daftarkan ke BAZNAS Prov. Kep. Bangka Belitung dengan mencatatkan data mustahiq ke dalam buku data mustahiq dan dimasukkan ke golongan-golongan tertentu.

d. Jika tidak mencapai syarat, maka calon mustahiq tidak didaftarkan ke BAZNAS Prov. Kep. Bangka Belitung. Sebelum melakukan pendistribusian dana zakat, Bidang Pendistribusian mencairkan dana dari bendahara dengan cara membuat surat permohonan pencairan dana 
sejumlah yang dibutuhkan berdasarkan data mustahiq dan hasil rapat.

e. Kemudian surat permohonan pencairan dana ditandatangani bidang pendistribusian dan diserahkan ke bendahara selanjutnya bendahara mencairkan dana sejumlah yang dibutuhkan dan menyerahkan ke bidang pendistribusian.

f. Proses Pendistribusian Setiap beberapa bulan sekali, Bidang pendistribusian menyalurkan uang hak mustahiq asnaf fakir miskin berdasarkan data mustahiq dengan jumlah uang yang diterima seorang mustahiq telah ditentukan oleh Ketua BAZNAS Prov. Kep. Bangka Belitung ketika melakukan penentuan santunan fakir miskin pada rapat awal tahun.

g. Bidang pendistribusian membuat daftar penerima manfaat rangkap 2 yang di tandatangani oleh mustahiq yang menerima santunan konsumtif atau bulanan dari BAZNAS Prov. Kep. Bangka Belitung.

\subsection{Use Case Diagram}

Berdasarkan proses bisnis yang diperoleh didapatkan proses yang akan dibuat di dalam sistem informasi pendistribusian zakat pada BAZNAS Prov. Kep. Bangka belitung terdapat 9 proses, yaitu:

1. Entry Proposal

Proses ini digunakan untuk menginput proposal yang masuk ke BAZNAS Prov. Kep. Bangka Belitungnya

2. Entry Surveyor

Menu ini digunakan untuk menginput data orang yang melakukan survey ke mustahiqnya.

3. Entry Survey

Proses ini untuk menginput data survey yang didapatkan dari data mustahiq.

4. Entry Asnaf

Proses ini dilakukan untuk menginput data mustahiq yang terdata.

5. Cetak Daftar Terima

Proses ini digunakan untuk membuat bukti bahwa proposal mustahiq diterima

6. Cetak Permohonan Dana

Proses ini untuk mencetak surat permohonan dana yang harus dikeluarkan.

7. Entry Daftar Distribusi

Proses ini untuk mencetak surat permohonan dana yang didistribusikan.

8. Cetak Kuitansi Pengeluaran

Prosses ini sebagai bukti bahwa zakat sudah diterima oleh mustahiq

9. Cetak Laporan Tahunan

Proses ini sebagai bukti untuk laporan tahuna tentang penyaluran zakat yang sudah dilakukan dalam periode satu tahun. 


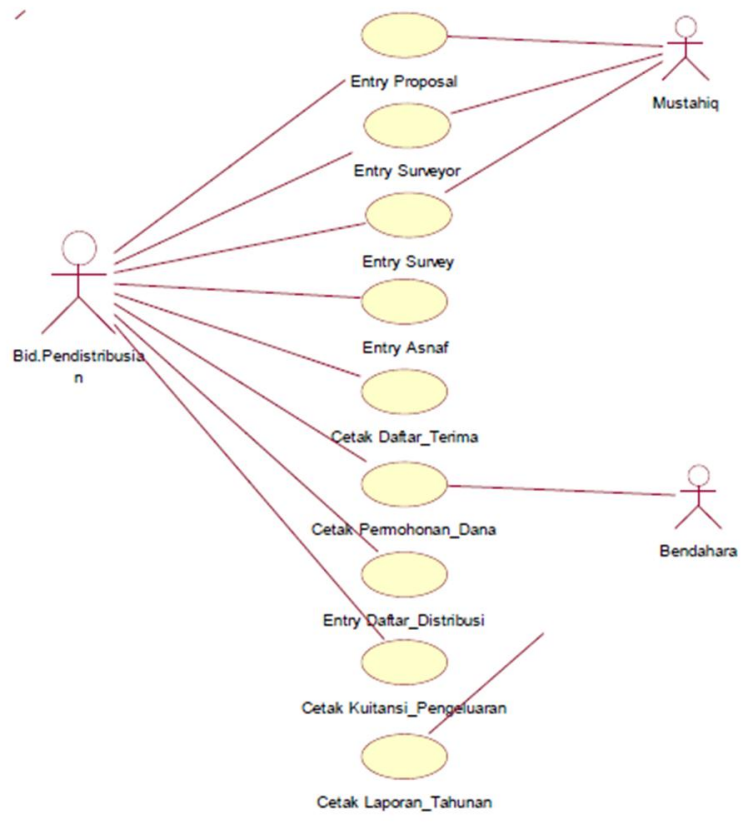

Gambar 1. Use Case Diagram Utomatisasi Penyaluran Zakat

\subsection{Diagram ER}

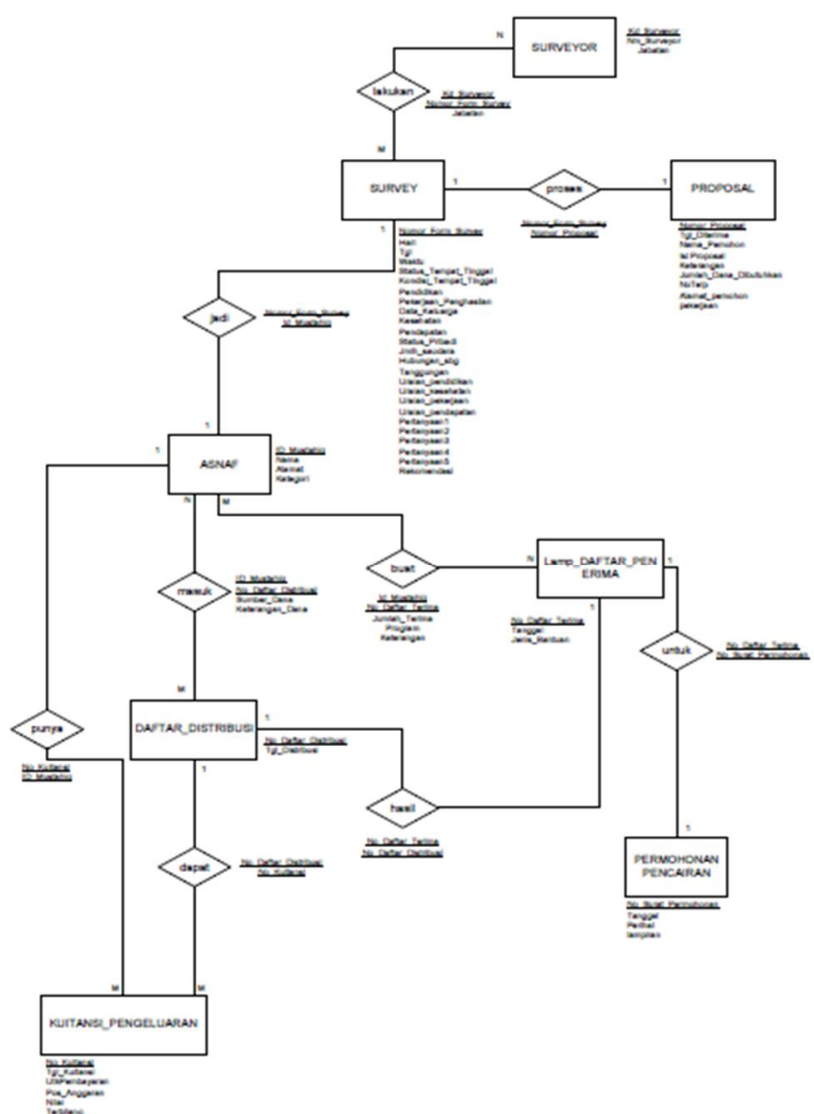

Gambar 2. Diagram ER Otomatisasi Penyaluran Zakat 
Diagram ER diatas menghasilkan 10 tabel dimana dari tabel tersebut digunakan untuk menyimpan data-data yang terdapat didalam proses Use Case Diagram, Tabel tersebut adalah:

Tabel 1. Hasil Trasnformasi Diagram ER

\begin{tabular}{|c|c|}
\hline Nama Tabel & Nama Field \\
\hline Surveyor & $\begin{array}{l}\text { Kd_Surveyor : Primary Key } \\
\text { Nm_Surveyor : Secondary Key } \\
\text { Jabatan : Secondary Key }\end{array}$ \\
\hline Survey & $\begin{array}{l}\text { Nomor_Form_Survey : Primary Key } \\
\text { Hari : Secondary Key } \\
\text { Tgl : Secondary Key } \\
\text { Waktu : Secondary Key } \\
\text { Status_Tempat_Tinggal : Secondary } \\
\text { Key } \\
\text { Kondisi_Tempat_Tinggal : Secondary } \\
\text { Key } \\
\text { Pendidikan : Secondary Key } \\
\text { Pekerjaan_Penghasilan : Secondary } \\
\text { Key } \\
\text { Data_Keluarga : Secondary Key } \\
\text { Kesehatan : Secondary Key } \\
\text { Pendapatan : Secondary Key } \\
\text { Status_Peribadi : Secondary Key } \\
\text { Jmlh_Saudara : Secondary Key } \\
\text { Hubungan_sbg : Secondary Key } \\
\text { Uraian_pendidikan : Secondary Key } \\
\text { Tanggungan : Secondary Key } \\
\text { Uraian_Kesehatan : Secondary Key } \\
\text { Uraian_Pekerjaan : Secondary Key } \\
\text { Uraian_Pendapatan : Secondary Key } \\
\text { Pertanyaan1 : Secondary Key } \\
\text { Pertanyaan2 : Secondary Key } \\
\text { Pertanyaan3 : Secondary Key } \\
\text { Pertanyaan4 : Secondary Key } \\
\text { Pertanyaan5 : Secondary Key } \\
\text { Rekomendasi : Secondary Key } \\
\text { Nomor_Proposal : Foreign Key }\end{array}$ \\
\hline Asnaf & $\begin{array}{l}\text { ID_Mustahiq : Primary Key } \\
\text { Nama : Secondary Key } \\
\text { Alamat : Secondary Key } \\
\text { Kategori : Secondary Key } \\
\text { Nomor_Form_Survey : Foreign Key }\end{array}$ \\
\hline Proposal & $\begin{array}{l}\text { Nomor_Proposal : Primary Key } \\
\text { Tgl_Diterima : Secondary Key } \\
\text { Nama_Pemohon : Secondary Key } \\
\text { Isi_Proposal : Secondary Key } \\
\text { Keterangan : Secondary Key } \\
\text { Jumlah_Dana_dibutuhkan : Secondary } \\
\text { Key }\end{array}$ \\
\hline
\end{tabular}

Yuyi Andrika, et., al [Otomatisasi Pendistribusian Zakat Pada Badan Amil Zakat Nasional Prov. Kep. Bangka Belitung] 


\begin{tabular}{|c|c|}
\hline & $\begin{array}{l}\text { No_Telp : Secondary Key } \\
\text { Alamat_Pemohon : Secondary Key } \\
\text { Pekerjaan : Secondary Key }\end{array}$ \\
\hline Daftar_Penerima & $\begin{array}{l}\text { No_Daftar_Terima : Primary Key } \\
\text { Tanggal : Secondary Key } \\
\text { Jenis Bantuan : Secondary Key }\end{array}$ \\
\hline Daftar_Distribusi & $\begin{array}{l}\text { No_Daftar_Distribusi : Primary Key } \\
\text { Tgl_Distribusi : Secondary Key }\end{array}$ \\
\hline Permohonan_Pencairan & $\begin{array}{l}\text { No_Surat_Permohonan : Primary Key } \\
\text { Tanggal : Secondary Key } \\
\text { Perihal : Secondary Key } \\
\text { Lampiran : Secondary Key } \\
\text { No_Daftar_Terima : Secondary Key }\end{array}$ \\
\hline Kuitansi_Pengeluaran & $\begin{array}{l}\text { No_Kuitansi : Primary Key } \\
\text { Tgl_Kuitansi : Secondary Key } \\
\text { UtkPembayaran : Secondary Key } \\
\text { Pos_Anggaran : Secondary Key } \\
\text { Nilai : Secondary Key } \\
\text { Id_Mustahiq }: \text { Foreign Key } \\
\text { No_Daftar_Distribusi : Foreign Key }\end{array}$ \\
\hline Masuk & $\begin{array}{l}\text { ID_Mustahiq }: \text { Foreign Key } \\
\text { No_Daftar_Distribusi : Foreign Key } \\
\text { Sumber_Dana : Secondary Key } \\
\text { Keterangan_dana : Secondary Key } \\
\text { Nilai_Terima : Secondary Key }\end{array}$ \\
\hline Buat & $\begin{array}{l}\text { ID_Mustahiq : Foreign Key } \\
\text { No_Daftar_Terima : Foreign Key } \\
\text { Jumlah_Terima : Secondary Key } \\
\text { Program : Secondary Key } \\
\text { Keterangan : Secondary Key }\end{array}$ \\
\hline
\end{tabular}

\subsection{User Interface}

Didalam user interface otomatisasi penyaluran zakat BAZNAS Prov. Kep. Bangka Belitung terdapat 4 Menu Utama, yaitu:

1. Master

Sub menu Master:

a. Entry Proposal

b. Entry Surveyor

c. Entry Asnaf

2. Transaksi

Sub Menu Transaksi:

a. Cetak Daftar Terima

b. Cetak Permohonan Dana

c. Cetak Kuitansi Pengeluaran

d. Entry Survey

e. Entry Daftar Distibusi

3. Laporan

Sub Menu Laporan: 
a. Cetak laporan Tahunan

Fungsi dari masing-masing user interface sudah dijelaskan di dalam use case diagram.

Sebagian user interface terdapat di bawah ini:

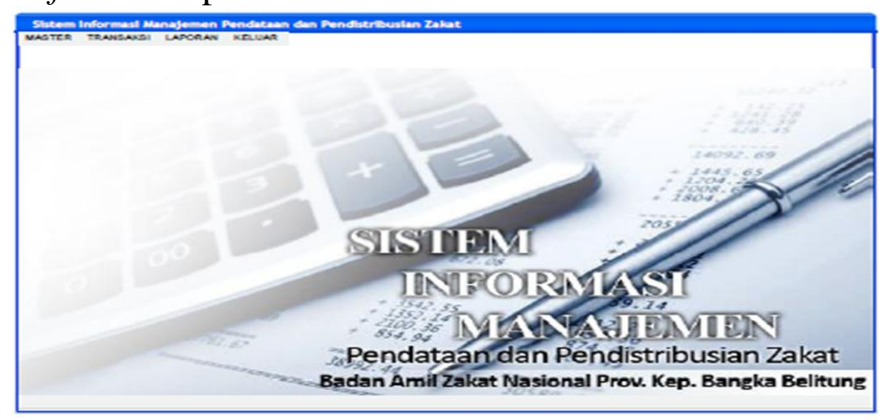

Gambar 3. User Interface Hal Utama

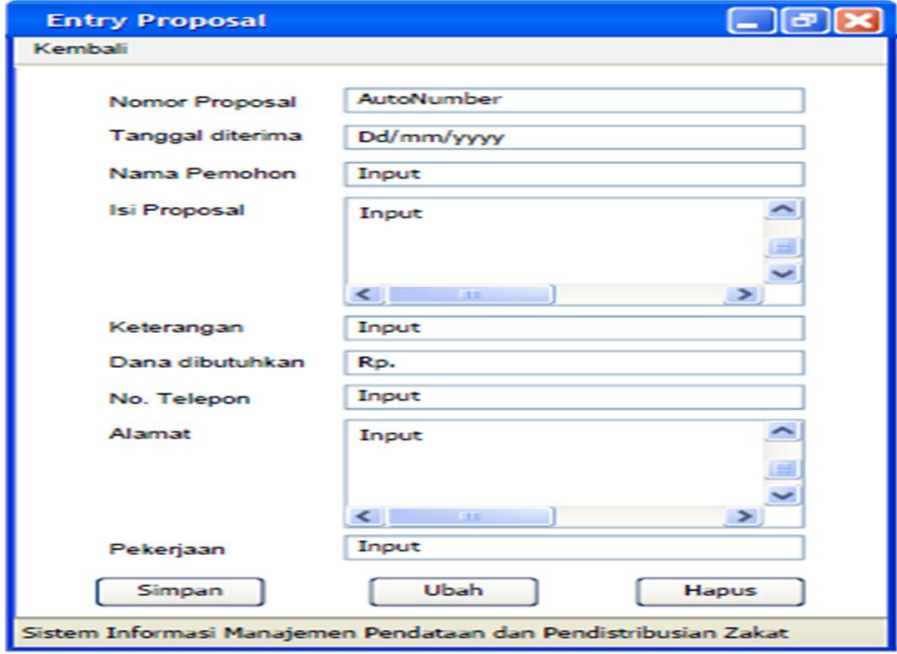

Gambar 4. UI Entry Proposal

\subsection{Pengujian Sistem}

Sistem otomatisasi penyaluran zakat diuji menggunakan Black Box, semua menu yang terdapat didalam otomatisasi dinyatakan sesuai dengan fungsinya. Adapun menu yang sudah diuji kesesuaian fungsi dapat dilihat sebagai berikut:

Tabel 2. Hasil Pengujian Sistem Informasi Otomatisasi Penyaluran Zakat

\begin{tabular}{ll}
\hline \multicolumn{1}{c|}{ Requirement yang Diuji } & Hasil \\
\hline Entry Proposal & Sesuai \\
Entry Asnaf & Sesuai \\
Entry Surveyor & Sesuai \\
Cetak Daftar Terima & Sesuai \\
Cetak Permohonan Dana & Sesuai \\
Cetak Kuitansi Pengeluaran & Sesuai \\
Entry Survey & Sesuai \\
Entry Daftar Distibusi & Sesuai
\end{tabular}


Adapun salah satu contoh bentuk pengujian dapat dilihat di bawah ini:

Tabel 3. Pengujian Layar Entry Data Proposal

\begin{tabular}{c|c|l|c}
\hline No & $\begin{array}{c}\text { Requirement } \\
\text { yang Diuji }\end{array}$ & \multicolumn{1}{c|}{ Butir Uji } & $\begin{array}{c}\text { Jenis } \\
\text { Pengujian }\end{array}$ \\
\hline 1 & Simpan proposal & $\begin{array}{l}\text { User melakukan penyimpanan } \\
\text { data proposal }\end{array}$ & Black Box \\
2 & Ubah proposal & $\begin{array}{l}\text { User melakukan ubah data } \\
\text { proposal }\end{array}$ & Black Box \\
3 & Hapus proposal & $\begin{array}{l}\text { User melakukan hapus data } \\
\text { proposal }\end{array}$ & Black Box
\end{tabular}

Tabel 4. Pengujian Layar Entry Data Proposal

\begin{tabular}{|c|c|c|c|}
\hline Requirement & Skenario Uji & Hasil yang Diharapkan & $\begin{array}{c}\text { Hasil } \\
\text { Pengujian }\end{array}$ \\
\hline $\begin{array}{c}\text { Simpan } \\
\text { proposal }\end{array}$ & $\begin{array}{l}\text { Simpan } \\
\text { proposal } \\
\text { (jika data benar) } \\
\text { Simpan } \\
\text { proposal } \\
\text { (jika data salah) }\end{array}$ & $\begin{array}{l}\text { Data akan tersimpan ke } \\
\text { database yaitu ke tabel } \\
\text { proposal } \\
\text { Tampil peringatan untuk } \\
\text { memperbaiki data yang } \\
\text { inputannya salah }\end{array}$ & Sesuai \\
\hline Ubah proposal & $\begin{array}{ll}\text { Ubah } & \text { data } \\
\text { proposal } & \text { (jika } \\
\text { data benar) } & \\
\text { Ubah } & \text { data } \\
\text { proposal } & \text { (jika } \\
\text { data salah) } & \end{array}$ & $\begin{array}{l}\text { Field yang diubah datanya } \\
\text { akan berubah dan tersimpan } \\
\text { di tabel proposal } \\
\text { Field yang diubah datanya } \\
\text { tidak akan berubah daan akan } \\
\text { memunculkan konfirmasi } \\
\text { kesalahan }\end{array}$ & Sesuai \\
\hline \multirow[t]{2}{*}{$\begin{array}{c}\text { Hapus } \\
\text { proposal }\end{array}$} & $\begin{array}{l}\text { Hapus data (jika } \\
\text { data benar) }\end{array}$ & $\begin{array}{l}\text { Data akan terhapus ke } \\
\text { database yaitu ke tabel } \\
\text { proposal }\end{array}$ & Sesuai \\
\hline & $\begin{array}{l}\text { Hapus data (jika } \\
\text { data salah) }\end{array}$ & $\begin{array}{l}\text { Data akan terhapus dari } \\
\text { database yaitu dari tabel } \\
\text { proposal }\end{array}$ & Sesuai \\
\hline
\end{tabular}

\section{KESIMPULAN}

Berdasarkan uraian dan pembahasan pada bab-bab sebelumnya, dapat ditarik kesimpulan bahwa:

a. Sistem Informasi manajemen pendistribusian zakat yang dibuat hanya mencakup ruang lingkup kegiatan di bidang pendistribusian zakat,

b. Sistem yang dibangun membantu bidang pendistribusian dalam proses pencatatan proposal, hingga proses pelaporan hasil distribusi,

c. Sistem informasi manajemen pendistribusian zakat sudah merupakan sistem yang terkomputerisasi dan menjadi solusi pencatatan data yang lebih rapi. 


\section{SARAN}

Sistem yang dibangun masih memiliki kekurangan dan keterbatasan, oleh sebab itu ada beberapa hal yang perlu dikembangkan oleh peneliti selanjutnya agar sistem dapat berguna menjadi lebih baik, antara lain:

a. Dalam pelaporan, akan lebih baik jika disesuaikan dengan format pelaporan berdasarkan PSAK 109,

b. Perlu ditambahkan fitur-fitur keamanan data agar data tidak bisa dimanipulasi oleh pihak yang tidak bertanggung jawab,

c. Perlunya fitur Autobackup untuk membackup segala data-data transaksi yang telah terekam agar lebih menjamin keamanan data jika dikemudian hari terjadi kerusakan atau bencana alam yang mengakibatkan hilangnya seluruh data, dan

d. Menambahkan metode Sistem Pendukung Keputusan (SPK) untuk menilai kelayakan calon mustahiq sebelum menjadi mustahiq dan tercatat di database Sistem yang dibangun.

\section{DAFTAR PUSTAKA}

[1] Damanhur, 2014. "Model Penyaluran Zakat Produktif Dalam Meningkatkan Kesejahteraan Mayarakat di Propinsi Aceh", Prosiding Seminar Nasional Ekonomi, 18 20 November 2014.

[2] Rahim Syamsuri, 2017. "Pengelolaan Zakat Perusahaan", Jurnal Akuntansi Multiparadigma (JAMAL), Vol. 8, No. 1, April 2017, Malang.

[3] Ichsan Nurul, 2019. “ Efektifitas Penyaluran Dana ZIS: Studi Kasus pada SMA Terbuka Binaan LAZ Sukses Kota Depok”, Journal of Islamic Economics Al Falah, Vol. 11, No. 21, Mei 2019, Curup, 2019.

[4] Putra Eka Julian Rudi, 2015. "Aplikasi E-Zakat Penerimaan dan Penyaluran Menggunakan Fuzzy C-Means (Studi Kasus: LAZISMU Pekanbaru)”, Jurnal Teknologi Informasi \& Komunikasi Digital Zone, Vol. 6, No. 2, November 2015, Riau, 2015.

[5] Supriadi Deddy, 2018. "Perancangan Sistem Informasi Zakat Berbasis Web", IJCIT (Indonesian Journal on Computer and Information Technology), Vol. 3, No. 1, Mei 2018, Tasikmalaya, 2018.

[6] Sukamto dan Shalahuddin. 2013. "Rekayasa Perangkat Lunak Struktur dan Berorientasi Objek” Informatika, Bandung.

[7] Indriyani Fintri, 2018. "Sistem Informasi Pengelolaan Zakat Profesi pada Badan Amil Zakat Nasional (BAZNAS) Kabupaten Bogor”. JUSTIN (Jurnal Sistem dan Teknologi Informasi), Vol., No. 4, Oktober 2018, Tanjungpura, 2018.

[8] Sahrial Rysa, 2018. "Rancang Bangun Sistem Informasi Zakat Infaq Shodaqoh Mengunakan Metodologi Extreme Programming”, Jurnal Buana Informatika, Vol. 9, No. 1, Januari 2018, Atmajaya Yogyakarta, 2018. 